\title{
ASPEK EKONOMI USAHA TRANSPORTASI PERAHU BERMOTOR ANTAR PULAU DI MUARA SUNGAI TONDANO KOTA MANADO
}

\author{
Kevin M. Rompis ${ }^{1}$; Jeannette F. Pangemanan²; Victoria E.N. Manoppo² \\ 1)Mahasiswa Fakultas Perikanan dan IImu Kelautan Universitas Sam Ratulangi Manado \\ 2)Staff Pengajar Fakultas Perikanan dan IImu Kelautan Universitas Sam Ratulangi Manado \\ Koresponden email : kevinrompis@gmail.com
}

\begin{abstract}
The purpose of this study was to find out and explain motorized boat transportation activities, while also knowing and analyzing the economic conditions of motorized boat transport entrepreneurs at the mouth of the Tondano river in Manado city. The method used in this study is a survey, which is a critical observation and investigation to get good information on a particular problem. The population in this study was motorized boat transportation entrepreneurs in Tondano river estuary as many as 6 people. The results of research showed that motorized boat transportation business activities at Tondano River estuary began at 08.00 AM, economic aspects of motorized boat transportation business in Tondano river estuary includes: Investment capital of 2 engine units Rp. 200,000,000, -; fixed costs for maintenance costs amount to Rp. 6,5000,000 per year; Ship depreciation fee of Rp. 20,000,000,. The income earned by entrepreneurs from the marine taxi business is usually $R p .1,000,000,-R p .1,500,000$, - every day, local rates for crossing the island (taxi) such as to the island of Bunaken Rp. 30,000, and for Tourist Rp. 100.000, -, Manado Tua island and Nain island local tariff Rp. 25,000, and Tourist Rp. 50,000.
\end{abstract}

Key Words: Transportation, economic aspects, income, expenditure, Tondano River Estuary

\begin{abstract}
Abstrak
Tujuan penelitian ini adalah untuk mengetahui dan menjelaskan aktivitas transportasi perahu bermotor di muara sungai Tondano Kota Manado, selain itu juga mengetahui dan menganalisis kondisi ekonomi dari pengusaha transportasi perahu bermotor di muara sungai Tondano Kota Manado. Metode yang digunakan dalam penelitian ini adalah survey, yaitu suatu pengamatan dan penyelidikan yang kritis untuk mendapatkan keterangan yang baik terhadap suatu persoalan tertentu. Yang menjadi populasi dalam penelitian ini adalah pengusaha tranportasi perahu bermotor di muara sungai Tondano sebanyak 6 orang.Hasil penelitian yang dilakukan didapatkan bahwa aktivitas pekerjaan usaha tranportasi perahu bermotor di muara Sungai Tondano dimulai pada pukul 08.00 (pagi), Aspek ekonomi usaha transportasi perahu bermotor di muara sungai Tondano meliputi: Modal investasi 2 unit mesin Rp. 200.000.000; biaya tetap untuk biaya perawatan berjumlah Rp. 6.5000 .000 per tahun; biaya penyusutan kapal senilai Rp. 20.000.000;

Pendapatan yang diperoleh pengusaha dari usaha taxi laut biasanya Rp. $1.000 .000-R p .1 .500 .000$ setiap hari, tarif lokal untuk menyeberangi pulau (taxi laut) seperti ke pulau Bunaken Rp. 30.000, dan untuk Tourist Rp. 100.000, pulau Manado Tua dan pulau Nain tariflokal Rp. 25.000 dan Tourist Rp. 50.000.

Kata Kunci: Transportasi, aspek ekonomi, pendapatan, pengeluaran, Muara Sungai Tondano
\end{abstract}

\section{PENDAHULUAN}

Transportasi sudah ada sejak dahulu kala hingga saat ini. Transportasi ada dengan berbagai media perjalanan, yaitu melalui daratan, lautan dan udara. Sebagian besar transportasi dilakukan melalui daratan, namun tidak sedikit juga transportasi dilakukan melalui lautan, danau dan sungai. Transportasi sungai di Indonesia banyak dibutuhkan disebabkan wilayah daratan di Indonesia banyak dilalui dengan sungai. Transportasi sungai dilakukan mulai dengan bantuan fasilitas paling sederhana, yaitu rakit, perahu, perahu bermotor, speed boat, sampai penggunaan kapal kecil, sedang dan besar. Sarana transportasi perahu sudah sejak dahulu kala digunakan manusia untuk transportasi sungai. Alur-alur sungai menjadi bagian yang dilalui perahu menuju tempat tujuan.

Transportasi merupakan sektor kegiatan yang sangat penting karena berkaitan dengan kebutuhan setiap orang untuk melakukan pergerakan. Kebutuhan ini misalnya kebutuhan untuk mencapai lokasi kerja, lokasi sekolah, mengunjungi tempat hiburan atau pelayanan dan bahkan untuk bepergian ke luar kota. Transportasi tidak hanya 
mengangkut orang, tetapi juga untuk memindahkan barang dari satu tempat ke tempat lain.

$$
\text { Muara Sungai Tondano }
$$
merupakan salah satu sungai yang ada di Sulawesi Utara. Keberadaan sungai ini telah memberikan ruang aktivitas transportasi menggunakan sarana perahu bermotor. Khususnya pada Muara Sungai Tondano di Kota Manado. Sarana perahu bermotor telah digunakan sebagai alat transportasi antar pulau bagi masyarakat Kota Manado, misalnya menyeberangi laut untuk ke pulau yang ada di sekitaran Kota Manado yaitu pulau Bunaken, Montehage, Nain, dan Manado Tua.

Sosial ekonomi adalah kedudukan atau posisi seseorang dalam kelompok manusia yang ditentukan oleh jenis aktivitas ekonomi, pendapatan, tingkat pendidikan, jenis rumah tinggal, dan jabatan dalam organisasi (Abdulsyani, 1994).

\section{METODE PENELITIAN}

Metode dasar yang digunakan dalam penelitian ini survey, dimana suatu pengamatan atau penyelidikan yang kritis untuk mendapatkan keterangan yang baik terhadap suatu persoalan tertentu di dalam daerah atau lokasi tertentu yang dipolakan untuk memperoleh informasi yang dibutuhkan (Syamri, 2007).

Populasi dalam penelitian ini adalah keseluruhan pengusaha transportasi perahu bermotor antar pulau yang ada di muara sungai Tondano Kota Manado. Berdasarkan data dari kantor kelurahan dan hasil dari prasurvei bahwa pengusaha transportasi bermotor berjumlah 6 orang yang berusaha di muara sungai Tondano Kota Manado.

Data yang dikumpulkan meliputi data primer dan data sekunder. Data primer diperoleh dari pengusaha transportasi perahu bermotor melalui pengisian daftar pertanyaan atau kuisioner yang sudah disiapkan, wawancara dan pengamatan. Pengunaan kuisoiner dimaksudkan agar pertanyaan-petanyaan dapat diarahkan, sehingga tidak menyimpang dari tujuan penelitian. Wawancara yang dimaksudkan untuk meminta penjelasan mengenai keterangan-keterangan yang mendalam serta pelengkap pertanyaan yang tidak tercantum dalam kuisioner. Pengamatan yang dimaksudkan untuk membantu peneliti di dalam menjawab suatu pertanyaan yang tidak dapat dijawab oleh pengusaha dan untuk memeriksa kebenaran jawaban pengusaha.

Data sekunder diperoleh dari catatan-catatan yang ada di Kantor Kelurahan Sindulang Satu, Kantor Kecamatan Tuminting, Kantor DKP Kota Manado dan DKP Provinsi Sulawesi Utara, Kantor BPS Provinsi Sulawesi Utara, serta kantor lainnya yang berhubungan dengan penelitian ini.

Analisis data hasil penelitian dibedakan dalam dua macam, yaitu analisis kuantitatif dan analisis kualitatif (Fathoni, 2006). Analisis kuantitatif merupakan pengolahan data dengan menggunakan perhitungan matematis sederhana seperti penjumlahan, pengurangan, perkalian, angka rata-rata, persentase $(\%)$ dan sebagainya, yang meliputi analisis usaha aspek keuangan, sumberdaya manusia, operasi/produksi dan pemasaran. Sedangkan analisis kualitatif adalah pengolahan data yang dilakukan melalui pertimbanganpertimbangan logika dengan bahasabahasa penulis yang sistematis. Data yang telah dianalisis kemudian diinterpretasikan sebagai hasil penelitian, yang meliputi wawancara, 
analisis dokumen, diskusi, atau observasi pertimbangan-pertimbangan logika dengan bahasa-bahasa penulis yang sistematis.

\section{HASIL DAN PEMBAHASAN}

\section{Aktivitas Transportasi Laut}

Aktivitas transportasi laut sesuai dengan hasil penelitian yang didapat, mereka memulai pekerjaannya pada pukul 08.00 (pagi), karena di pagi hari banyak masyarakat yang menggunakan sarana transportasi perahu bermotor untuk melakukan aktivitas baik di Kota Manado maupun di Pulau Bunaken, Nain dan Manado Tua.

Untuk perjalanan menyeberangi laut hanya dilakukan 1 kali dalam sehari, dalam usaha transportasi laut pengusaha menggunakan kapal motor sebagai sarana untuk mengangkut para penumpang dan biasanya bisa mengangkut 20 sampai 40 penumpang dan juga pengiriman bahan sembako

\section{Tarif Penumpang}

Tarif per penumpang yang menggunakan sarana Transportasi Laut (Taxi) di Muara Sungai Jondano Kota Manado dapat dilihat pada Tabel 2.

Tabel 2. Tarif Per penumpang Dalam Sekali Melakukan Perjalanan

\begin{tabular}{|c|l|r|r|}
\hline \multirow{2}{*}{ No. } & \multirow{2}{*}{ CTujuan } & \multicolumn{2}{|c|}{ Harga (Rp.) } \\
\cline { 3 - 4 } & & \multicolumn{1}{c|}{ Lokal } & \multicolumn{1}{c|}{ Turis } \\
\hline 1. & Manado-Bunaken & 30.000 & 100.000 \\
\hline 2. & Manado-Manado Tua & 25.000 & 50.000 \\
\hline 3. & Manado-Pulau Nain & 25.000 & 50.000 \\
\hline
\end{tabular}

Sumber: Data Primer (2019)

Berdasarkan Tabel 2 dapat dikatakan bahwa masing-masing tempat tujuan memiliki harga yang berbeda tergantung lokasi atau tujuan yang akan dituju oleh penumpang, selain itu harga untuk masyarakat lokal dan interlokal berbeda, tentunya ini memberikan keuntungan yang lumayan untuk pemilik usaha Transportasi Laut (Taxi) berupa kapal motor yang ada di Kelurahan Sindulang Satu Kecamatan Tuminting Kota Manado.

\section{Aspek Ekonomi Usaha Transportasi Perahu Bermotor}

Pada Setiap usaha-usaha tertentu pasti memerlukan biaya dan pada usaha transportasi perahu bermotor ini biayabiaya yang mereka perlu menurut data di lapangan, sebagai berikut.

\section{Investasi}

Menjalankan suatu usaha hal yang paling penting yang harus disediakan oleh seorang pengusaha yaitu modal yang merupakan dana awal dalam membentukan suatu usaha. Adapun modal yang diperlukan sebagai dana investasi yaitu untuk pengadaan 1 unit perahu bermotor besama 2 unit mesinnya berjumlah Rp. 200.000.000.

\section{Struktur Biaya}

Untuk melakukan usaha transportasi, selain modal investasi yang perlukan pemilik juga harus menyediakan biaya-biaya lain, biayabiaya tersebut adalah biaya tetap (fix cost) dan biaya tidak tetap (variable cost).

\section{Biaya Tetap}

Biaya tetap (fix cost) meliputi biaya perawatan dan penyusutan dalam hal ini biaya penyusutan itu 10 tahun (10\% dari investasi) hasilnya Rp. 20.000 .000 biaya perawatan berjumlah Rp. 6.500 .000 / tahun yang digunakan.

\section{Biaya Perawatan Perahu Bermotor}

Menurut hasil penelitian yang didapat biaya perbaikan kapal dapat dilihat pada Tabel 3. 
Tabel 3. Biaya Perbaikan Perahu Bermotor Dalam Setahun

\begin{tabular}{|c|l|r|}
\hline No. & \multicolumn{1}{|c|}{ Uraian } & \multicolumn{1}{c|}{ Biaya (Rp) } \\
\hline 1. & Tukang & 1.000 .000 \\
\hline 2. & Kayu & 2.000 .000 \\
\hline 3. & Cat Warna & 1.000 .000 \\
\hline 4. & Lem & 500.000 \\
\hline 5. & Service Mesin & 2.000 .000 \\
\hline \multicolumn{2}{|r|}{ Jumlah } & 6.500 .000 \\
\hline
\end{tabular}

Sumber: Data Primer (2019)

Berdasarkan pada Tabel, biaya perbaikan perahu dalam 1 tahun sebesar Rp. 6.500.000-, sudah termasuk dengan biaya tukang perahu, kayu, lem dan cat.

\section{Biaya Penyusutan Kapal}

Menurut hasil penelitian yang didapat biaya perbaikan perahu dapat dilihat pada Tabel 4 berikut:

Tabel 4. Biaya Penyusutan Perahu Bermotor Dalam Setahun

\begin{tabular}{|c|l|c|c|c|}
\hline No & Uraian & Harga & $\begin{array}{c}\text { Umur } \\
\text { Ekonomis }\end{array}$ & $\begin{array}{c}\text { Harga } \\
\text { penyusutan/ } \\
\text { tahun }\end{array}$ \\
\hline 1. & Perahu & 150.000 .000 & 10 & 15.000 .000 \\
\hline 2. & Mesin & 50.000 .000 & 10 & 5.000 .000 \\
\hline \multicolumn{4}{|c|}{ Jumlah } & 20.000 .000 \\
\hline
\end{tabular}

Sumber: Data Primer (2019)

Tabel 4 menunjukan bahwacbaik perahu bermotor maupun mesinnya bisa di gunakan untuk pengusaha tersebut dalam kurun waktu 10 tahun artinya bahwa kapal dan mesin ini bila dijual tidak akan berarti lagi. Memang masa pakai kapal dan mesin digunakan dalam jangka waktu lama karna mereka melakukan perawatan berupa mengganti kayu.

\section{Biaya Tidak Tetap}

Biaya tidak tetap (variable cost) adalah biaya-biaya yang dikeluarkan tergantung pada trip usaha transportasi perahu bermotor yang dilakukan 4 trip dalam seminggu, sedangkan untuk usaha transportasi perahu bermotor yang dilakukan sebulan sebanyak 16 trip, dan dalam setahun hanya dilakukan sebanyak 160 trip. Untuk lebih terperinci maka biaya tidak tetap pertahun dari usaha transportasi perahu bermotor adalah sebagai 5 berikut.

Tabel 5. Biaya Pengeluaran perTrip Usaha Transportasi Perahu Bermotor di Muara Sungai Tondano Kota Manado.

\begin{tabular}{|l|l|r|r|}
\hline No. & Uraian & Biaya & Biaya/tahun \\
\hline 1. & Bensin & 800.000 & 128.000 .000 \\
\hline 2. & Makanan - Minuman & 100.000 & 32.000 .000 \\
\hline 3. & ABK & 300.000 & 48.000 .000 \\
\hline 4. & Oli & 170.000 & 850.000 \\
\hline Jumlah & 1.370 .000 & 208.850 .000 \\
\hline
\end{tabular}

Sumber: Hasil Pengolahan Data (2019)

Berdasarkan Tabel 5. biaya pengeluaran usaha transportasi perahu bermotor dalam sekali melakukan perjalanan menyeberangi laut untuk bensin Rp. 800.000. Adapun pengeluaran-pengeluaran seperti makanan, oli dan juga bensin. Pengetuaran ini bila dibandingkan dengan pendapatan cukup layak mendapat profit yang lumayan

\section{Pendapatan}

Pendapatan setiap usaha transportasi perahu bermotor tidak menentu, dikarenakan para penumpang yang ada tidak setiap hari melakukan trip ke pulau-pulau. Pendapatan yang diperoleh dari usaha transportasi perahu bermotor terdiri dari taxi perahu biasanya Rp. 1.000 .000 - Rp. 1.500.000 setiap hari, keuntungan lainnya berupa pengiriman barang untuk taxi laut yang harganya Rp. 10.000 per barang. Ada pula keuntungan penyewaan kapal yang dilakukan masyarakat lokal maupun wisatawan (tourist) untuk bertamasya (liburan) ke tempat wisata yang ada di Pulau Bunaken, Pulau Nain, dan Pulau Siladen yang biasanya dibayar dengan harga Rp. 3.000.000 - Rp. 4.000.000 per hari. Pendapatan per trip dari usaha transportasi perahu bermotor seperti hasil analisis berjumlah rata-rata $R p$. 
1.090.000. Dengan demikian maka untuk mendapatkan berapa hasil pendapatan pertahun dari usaha transportasi perahu bermotor adalah 160 trip x Rp. 1.090 .000 $=$ Rp. 174.400.000. Walaupun pendapatan pertahun jumlahnya besar namun usaha ini justrul sangat berhasil bila ada pemasukan dari hasil pendapatan pinitipan barang karna tenaga yang dikeluarkan sedikit hasilnya banyak.

\section{Transportasi Perahu Bermotor (Taxi Laut)}

Taxi laut sebagai sarana usaha transportasi masyarakat untuk melakukan aktivitas keluar pulau yang berada Sulawesi Utara khususnya Kota Manado. Untuk menyeberangi ke pulau pulau tarif yang diberikanan untuk sekali menyeberangi ke pulau yang ada berbeda-beda, misalnya ke pulau bunaken untuk masyarakat lokal Rp. 30.000 dan untuk Tourist Rp. 100.000, dan untuk pulau Manado Tua, Nain dikenakan dengan tarif yang sama untuk masyarakat lokal Rp. 25.000 dan tourist Rp. 50.000 dalam sekali melakukan perjalanan.

\section{Penyewaan Perahu Bermotor}

Penyewaan perahu bermotor biasanya dilakukan masyarakat lokal ataupun torist pada waktu libur (weekend) untuk melakukan trip ke 3 tempat wisata yang ada di pulau Bunaken, Nain, dan Lihaga, biasanya penyewaaan kapal ini diberikan tarif Rp. 3.000 .000 - Rp. 4.000 .000 per hari bagi para penumpang yang mengikuti trip. Trip biasanya berangkat pada pukul 9 pagi sampai 5 sore.

\section{Penitipan Barang}

Selain Taxi laut dang penyewaan kapal, usaha perahu bermotor juga bisa menitipkan barang berupa bahan-bahan warung untuk dijual di pulau Bunaken ataupun Manado Tua yang diberikan tarif Rp. 10.000 per barang.

Pendapatan usaha perahu ini yaitu:

\begin{tabular}{|c|c|c|c|}
\hline $\begin{array}{c}\text { Perahu } \\
\text { Taxi }\end{array}$ & $\begin{array}{c}\text { Penitipan } \\
\text { Barang }\end{array}$ & $\begin{array}{c}\text { Penyewaan } \\
\text { Perahu }\end{array}$ & Total \\
\hline 174.400.000 & 28.000 .000 & 273.000 .000 & 475.400 .000 \\
\hline \multicolumn{4}{|l|}{ Sumber: Hasil Pengolahan Data (2019) }
\end{tabular}

\section{Hasil Bersih Usaha Perahu Bermotor per Tahun}

Untuk mengetahui hasil bersih atau hasil yang diperoleh dalam setahun usaha perahu bermotor, yaitu:

\begin{tabular}{|c|c|c|}
\hline Pendapatan & Biaya Total & Hasil bersih \\
\hline 475.400 .000 & 235.350 .000 & 240.050 .000 \\
\hline
\end{tabular}

Hal ini menunjukkan bahwa hasil bersib berjumalah Rp. 217.990.000, ini merupakan jumlah yang cukup signifikan bila dihubungkan dengan pemenuhan keadaan perekonomian keluarga. Sehingga para pengusaha bisa dikatakan hidupnya sudah mapan dan tempat tinggal lebih dari standart kehidupan masyarakat sekitar.

\section{KESIMPULAN}

Aktivitas transportasi perahu bermotor di muara sungai Tondano Kota Manado dimulai pada pukul 08.00 (pagi). Untuk perjalanan menyeberangi laut hanya dilakukan 1 kali dalam sehari, pengusaha menggunakan kapal motor sebagai sarana untuk mengangkut para penumpang dan biasanya bisa mengangkut 15 sampai 30 penumpang dan ada pula penumpang lokal ataupun turis yang menyewa kapal seharian penuh untuk mengelilingi 3 destinasi mulai pagi dan pulang atau selesai pada sore hari dengan biaya yang berbeda pula.

Kondisi ekonomi dari usaha transportasi perahu bermotor di muara sungai Tondano Kota Manado antara lain: Biaya, yang menggunakan sarana 
Transportasi Laut (Taxi) dari penyewaaan kapal dari pagi sampai sore untuk melakukan perjalananan mengelilingi 3 pulau yaitu sebesar Rp. 3.000 .000 - Rp. 4.000.000. Pendapatan total usaha perahu bermotor di muara sungai Tondano Rp. 453.340.000 yang meliputi: Perahu Taxi Rp. 174.400.000, Penyewaan Perahu Rp. 273.000.000, Penitipan Barang Rp. 28.000.000 dengan total Rp. 475.400 .000

\section{DAFTAR PUSTAKA}

Abbas, Salim. 2000. Manajemen Transportasi. Cetakan Pertama. Edisi Kedua. Ghalia Indonesia. Jakarta.

Afrida, BR. 2003. Ekonomi Sumber Daya Manusia. Jakarta. Ghalia Indonesia

Fathoni. 2006. Manajemen Sumber Daya Manusia. Bandung

Ihsan, Fuad. 2003. Dasar-dasar Kependidikan Komponen MKDK. Jakarta: Rineka Cipta.
Linton, Ralph. 1984. Antropologi Suatu Penyelidikan Tentang Manusia. Bandung: CV Jemmars

Miro, F. 2005. Perencanaan Transportasi Untuk Mahasiswa, Perencana, dan Praktisi. Erlangga. Jakarta

Moleong. 2005. Metodologi Penelitian Kualitatif, Bandung

Riduwan. 2004. Metode dan Teknik Menyusun Tesis. Bandung

Samuelson, Paul A dan Nordhaus, William D. 2004. Ilmi Makro Ekonomi. Jakarta PT. Media Edukasi.

Sastropraja. 1991. Kamus Istilah Pendidikan Umum. Penerbit Usaha Nasional. Surabaya: Indonesia

Supardi. 2006. Penelitian Tindakan Kelas. Jakarta.

Suroto, 2000. Strategi Pembangunan dan Perencanaan Kesempatan Kerja. Yogyakarta: Gajah Mada University.

Syamsuri, 2007. IPA Biologi. Jakarta: PT Elangga.

Walgito. 2010. Pengantar Psikolog Umum. Yogyakarta. 